\title{
Determination of the optimal case definition for the diagnosis of end-stage renal disease from administrative claims data in Manitoba, Canada
}

\author{
Paul Komenda MD MHA, Nancy Yu PhD, Stella Leung MSc, Keevin Bernstein MD, James Blanchard PhD, \\ Manish Sood MD, Claudio Rigatto MD MSc, Navdeep Tangri MD PhD
}

See related research article by Komenda and colleagues at www.cmajopen.ca/lookup/doi/10.9778/cmajo.20130034

\section{Abstract}

Background: End-stage renal disease (ESRD) is a major public health problem with increasing prevalence and costs. An understanding of the long-term trends in dialysis rates and outcomes can help inform health policy. We determined the optimal case definition for the diagnosis of ESRD using administrative claims data in the province of Manitoba over a 7-year period.

Methods: We determined the sensitivity, specificity, predictive value and overall accuracy of 4 administrative case definitions for the diagnosis of ESRD requiring chronic dialysis over different time horizons from Jan. 1, 2004, to Mar. 31, 2011. The Manitoba Renal Program Database served as the gold standard for confirming dialysis status.

Results: During the study period, 2562 patients were registered as recipients of chronic dialysis in the Manitoba Renal Program Database. Over a 1-year period (2010), the optimal case definition was any 2 claims for outpatient dialysis, and it was $74.6 \%$ sensitive (95\% confidence interval [Cl] $72.3 \%-76.9 \%)$ and $94.4 \%$ specific $(95 \% \mathrm{Cl} 93.6 \%-95.2 \%)$ for the diagnosis of ESRD. In contrast, a case definition of at least 2 claims for dialysis treatment more than 90 days apart was $64.8 \%$ sensitive $(95 \% \mathrm{Cl} 62.2 \%-67.3 \%)$ and $97.1 \%$ specific $(95 \% \mathrm{Cl} 96.5 \%-97.7 \%)$. Extending the period to 5 years greatly improved sensitivity for all case definitions, with minimal change to specificity; for example, for the optimal case definition of any 2 claims for dialysis treatment, sensitivity increased to $86.0 \%(95 \% \mathrm{Cl} 84.7 \%-87.4 \%)$ at 5 years.

Conclusion: Accurate case definitions for the diagnosis of ESRD requiring dialysis can be derived from administrative claims data. The optimal definition required any 2 claims for outpatient dialysis. Extending the claims period to 5 years greatly improved sensitivity with minimal effects on specificity for all case definitions.

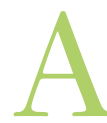

dministrative claims data represent an important repository of information on health care utilization in a single-payer health care system. ${ }^{1}$ Administrative databases have several potential advantages over traditional sources of clinical data (i.e., patient charts, disease-specific registries and electronic medical records) because they represent a more universal source of population-level data and document every interaction in the health care system uniformly. ${ }^{2-4}$ Despite these advantages, administrative databases must be validated against traditional sources of clinical data to develop robust case definitions. ${ }^{3,5,6}$ These definitions can then allow a variety of innovative epidemiologic applications, including linkage with other existing population-level datasets, and can help researchers and policy-makers gain new insights into the burden of disease. ${ }^{2,3}$

End-stage renal disease (ESRD) is a major public health problem associated with high rates of morbidity and mortality and significant costs to the health care system. ${ }^{7-10}$ Patients with ESRD who receive chronic dialysis typically engage the health care system thrice weekly (for facility-based hemodialysis), and peritoneal dialysis and hemodialysis have unique procedural codes. This disease state therefore provides an ideal situation to validate administrative case definitions against program-level data or data from a disease registry.

Previous investigators have developed case definitions for ESRD and earlier stages of chronic kidney disease. ${ }^{3,4}$ These

Competing interests: None declared.

This article has been peer reviewed.

Correspondence to: Navdeep Tangri, ntangri@sogh.mb.ca

CMAJ Open 2015. DOI:10.9778/cmajo.20140006 
definitions were internally validated in single jurisdictions over a limited period and in dialysis populations that were older and largely white. External validation of previously developed definitions, as well as exploration of accuracy over different time horizons, is needed to determine the most generalizable case definition for use across provinces and countries. We conducted this study to determine the optimal case definition for ESRD requiring chronic dialysis using administrative claims data in the province of Manitoba over a 7-year period.

\section{Methods}

\section{Study population}

The province of Manitoba, Canada, has a population of 1.2 million people. It has a universal health care system (Manitoba Health), which processes and maintains all claims for health care use in the province in a secured, centralized repository. ${ }^{11}$ The study cohort consisted of all patients covered by Manitoba Health who were more than 18 years of age from Jan. 1, 2004, to Mar. 31, 2011.

\section{Sources of data}

\section{Physician claims database}

Each physician claim includes the patient's identification number, the date of service and a 3-digit International Classification of Diseases, 9th revision, clinical modification (ICD9-CM) code for the physician-assigned diagnosis. Each record of admission to hospital includes the patient's identification number, the dates of admission and discharge, and the diagnostic codes listed on the discharge abstract. Before 2004, up to 16 diagnoses were recorded using 5-digit ICD-9-CM codes; beginning in 2004, up to 25 diagnoses were recorded using codes from the Canadian enhancement of the International Statistical Classification of Diseases and Related Health Problems, 10th revision (ICD-10-CA). In addition, Manitoba Health maintains a population registry that is updated when a person moves into or out of the province, changes marital or family status, or dies. ${ }^{11,12}$

To identify residents receiving dialysis in the Manitoba Health database, we searched all physician claims from Jan. 1, 2004, through Mar. 31, 2011, by tariff codes for initial dialysis (9798, 9801, 9805, 9806), subsequent dialysis (9799, 9802, 9807, 9819) and home dialysis (9821).

\section{Manitoba Renal Program Dialysis Registry}

The Manitoba Renal Program is the sole provider of dialysis and kidney health prevention services in the province. The program consists of more than 800 employees, including 23 actively practising nephrologists. Since January 2004, it has maintained a comprehensive database of all patients receiving chronic (> $90 \mathrm{~d}$ ) outpatient dialysis, including start and end dates, and detailed demographic and comorbidity data. The quality of these data is adjudicated at formal interprofessional rounds on a weekly basis. The validation of this database has been described elsewhere, ${ }^{13}$ and the database has been used extensively in published epidemiologic studies. ${ }^{13-15}$

\section{Case definitions}

Definitions of disease states and diagnoses based on administrative data sources must be validated with the use of traditional sources of clinical data (i.e., patient charts, diseasespecific registries, electronic medical records). ${ }^{12} \mathrm{We}$ developed the following 4 administrative case definitions for the diagnosis of ESRD, varying the number of claims for continuous outpatient dialysis used to define the diagnosis: (a) at least 1 claim; (b) any 2 claims; (c) any 2 claims at least 90 days apart; and (d) any 2 claims at least 90 days apart with no gaps in treatment greater than 21 days. The definitions were based on a previous validation study that used administrative data to define ESRD. ${ }^{3}$ These case definitions are a conventional standard in administrative algorithms for defining ESRD. ${ }^{3,16} \mathrm{We}$ chose the study period of Jan. 1, 2004, to Dec. 31, 2010, based on the available, high-quality data from the Manitoba Renal Program for validation purposes.

\section{Statistical analysis}

We computed the sensitivity, specificity, and positive and negative predictive values for each case definition, using the Manitoba Renal Program data as the reference standard. In addition, we selected the optimal case definition based on sensitivity (> 80\%) and specificity (> 90\%) and determined the area under the receiver operating characteristic (ROC) curve for each case definition. We used the definition with the highest area under the curve to examine secular trends in ESRD in Manitoba; our findings are reported in a companion article. ${ }^{17}$

For each case definition, we first evaluated its accuracy over a 1-year period by matching patients registered in the Manitoba Renal Program in a calendar year (2010) with administrative claims for dialysis in the same year. We then extended the time horizon to identify claims over 3, 5 and 7 years.

In sensitivity analyses, we examined performance by subgroups of age, sex, ethnicity (First Nations v. non-First Nations) and primary diagnosis of ESRD (diabetes v. glomerulonephritis). Ethnicity was self-reported in the Manitoba Renal Program registry or through registration at Manitoba Health, and diabetes and glomerulonephritis were defined using previously developed case definitions and ICD-9 and ICD-10 codes. ${ }^{18,19}$

We performed all analyses using SAS version 9.

\section{Ethics approval}

This study received approval from the health research ethics boards of the University of Manitoba and the Winnipeg Regional Health Authority. Approval from the Health Information Privacy Committee of Manitoba Health was also obtained, and data-sharing agreements were signed between these institutions.

\section{Results}

During the study period of January 2004 to December 2010, the Manitoba Renal Program database had 2582 registered patients (Table 1), including 1661 patients who had prevalent disease at the start of 2004 . The mean age of the study popu- 
lation was 59.7 (standard deviation 15.9 ) years, and $40.9 \%$ of the patients were 65 years or older. Overall, $54.1 \%$ of the patients were male, and the male:female ratio appeared to increase with age.

The performance of the 4 case definitions for the diagnosis of ESRD over a 1-year period is shown in Table 2. The most sensitive case definition was any 1 claim for outpatient dialysis (sensitivity $77.0 \%, 95 \%$ confidence interval [CI] 74.7-79.2; specificity $93.8 \%$, 95\% CI 92.9-94.7). The most specific and least sensitive case definition was any 2 claims for continuous outpatient dialysis more than 90 days apart with no gaps in treatment greater than 21 days $(53 \%$ sensitive $(95 \%$ CI 50.06-55.35), 98\% specific (95\% CI 96.93-98.06)). The case definition of any 1 claim had the highest accuracy $(88.5 \%$, 95\% CI $87.4 \%-89.6 \%)$ and agreement (kappa) score $(0.73$ (95\% CI 0.70-0.75) in calendar year 2010.

When we increased the time horizon for dialysis claims by 1 -year increments, the sensitivity of the case definitions improved considerably. Marked increases in sensitivity were noted after we extended the interval to 5 years (Table 3). In particular, for any 2 dialysis claims, the sensitivity increased from $74.6 \%$ (95\% CI $72.3 \%-76.9 \%$ ) to $86.0 \%$ (95\% CI $84.7 \%-$ $87.4 \%)$. There was a slight decline in specificity for this definition, from $94.4 \%$ (95\% CI 93.6\%-95.2\%) to $93.4 \%$ (95\% CI 92.9\%-93.9\%) when the interval was extended to 5 years.

Overall accuracy and agreement increased for all case definitions as the time intervals were extended (Appendix 1, available at www.cmajopen.ca/content/3/3/E264/suppl/DC1). The area under the ROC curve also improved when time intervals were extended, with the definition of any 2 outpatient dialysis claims having the highest value overall (area under the curve 0.8972, 95\% CI 0.8898-0.9045) (Appendix 2, available at www.cmajopen .ca/content/3/3/E264/suppl/DC1).

All of the case definitions were robust when analysed by

\section{Table 1: Age and sex distribution of patients in the} Manitoba Renal Program Dialysis Registry, 2004-2010

\begin{tabular}{|c|c|c|c|c|c|c|}
\hline \multirow{3}{*}{$\begin{array}{l}\text { Age, } y^{*} \\
\leq 24\end{array}$} & \multicolumn{5}{|c|}{ No. (\%) of patients } & \multirow{3}{*}{$\begin{array}{c}\begin{array}{c}\text { Male:female } \\
\text { ratio }\end{array} \\
0.84\end{array}$} \\
\hline & \multicolumn{2}{|c|}{ Total } & \multicolumn{2}{|c|}{ Men } & Women & \\
\hline & 55 & (2.2) & 25 & $(1.0)$ & $30 \quad(1.2)$ & \\
\hline $25-29$ & 59 & (2.3) & 29 & (1.1) & $30 \quad(1.2)$ & 0.97 \\
\hline $30-34$ & 86 & (3.4) & 38 & (1.5) & $48 \quad(1.9)$ & 0.79 \\
\hline 35-39 & 108 & $(4.2)$ & 61 & (2.4) & $47 \quad(1.8)$ & 1.30 \\
\hline $40-44$ & 154 & (6.0) & 79 & (3.1) & 75 (2.9) & 1.05 \\
\hline $45-49$ & 188 & (7.3) & 107 & $(4.2)$ & 81 (3.2) & 1.32 \\
\hline $50-54$ & 233 & (9.1) & 140 & (5.5) & 93 (3.6) & 1.50 \\
\hline $55-59$ & 313 & (12.2) & 183 & $(7.1)$ & $130(5.1)$ & 1.41 \\
\hline $60-64$ & 317 & (12.4) & 165 & (6.4) & $152(5.9)$ & 1.09 \\
\hline$\geq 65$ & 1049 & $(40.9)$ & 558 & $(21.8)$ & $491(19.2)$ & 1.14 \\
\hline Total & 2562 & (100.0) & 1385 & $(54.1)$ & $1177(45.9)$ & 1.18 \\
\hline \multicolumn{7}{|c|}{$\begin{array}{l}{ }^{*} \text { Mean age } \pm \text { standard deviation }=59.7 \pm 15.9 \text { overall, } 59.8 \pm 15.5 \text { for men and } \\
59.6 \pm 16.4 \text { for women. }\end{array}$} \\
\hline
\end{tabular}

age, sex, ethnicity and primary diagnosis of renal disease (Appendices 3 and 4, available at www.cmajopen.ca/content /3/3/E264/suppl/DC1). According to our predefined criteria of sensitivity greater than $80 \%$ and specificity greater than $90 \%$, the optimal case definition was any 2 dialysis claims (overall accuracy of greater than $90 \%$ in all tested subgroups).

\section{Interpretation}

Our study showed that valid case definitions of ESRD can be derived from administrative claims data. These claims data may serve as a valuable tool to track the epidemiology of kidney failure at a population level. We found that extending the time interval (up to 7 years) improved the sensitivity and overall accuracy of the case definitions for chronic dialysis status, with a minimal change in specificity. Accuracy and agreement scores were suboptimal compared with the gold standard Manitoba Renal Program database when only a 1-year period was used. As such, we recommend that a 5- or 7-year interval for claims be used in case-finding for patients with ESRD in administrative datasets.

Over a 1-year period, the most sensitive case definition (any 1 claim for outpatient dialysis) achieved a sensitivity of $77 \%$, specificity of $94 \%$ and an overall accuracy of $88 \%$. Conversely, the most specific definition (at least 2 claims for dialysis treatment at least 90 days apart, with no gaps in treatment greater than 21 d) had a sensitivity of $53 \%$, specificity of $98 \%$ and an overall accuracy of $83 \%$.

Our findings were slightly inferior to the sensitivity and accuracy of similar case definitions in the province of Alberta, ${ }^{3}$ which highlights the need for external validation in individual jurisdictions where coding and billing practices, as well as registry accuracy, may differ. In contrast to the findings from Alberta, we found minimal gains in specificity with the addition of a 21-day gap limit to one of the case definitions that spanned 90 days, and a significant loss in sensitivity and overall accuracy. The loss in sensitivity was notable at 1 year but became even more pronounced when the time interval was extended to 5 and 7 years. This suggests that researchers seeking the most specific case definition of ESRD (to avoid falsepositive cases) would not benefit from including a 21-day gap limit and should simply include all patients with at least 2 outpatient claims at least 90 days apart. However, if the most sensitive case definition is desired, a definition based on any 1 outpatient dialysis treatment may be preferable, with the caveat that cases of acute kidney injury (false-positive ESRD) requiring a single dialysis treatment might be identified.

Our findings on the accuracy of the case definitions for ESRD were similar to those from other provinces $^{3,20}$ when examined over a 1 -year period, but they were markedly superior when we extended the period to 3, 5 and 7 years. Extending these periods allowed us to achieve a high degree of accuracy $(>90 \%)$ for multiple case definitions, which could be used if sensitivity or specificity was primarily desired. We suspect that these increases in accuracy were likely due to dataentry delays in the capture of incident cases in the patient registry, and to billing errors in administrative data. Errors in 
entering personal health identifiers for medical billing are common and often result in claims being rejected and returned to the submitting physician. The claims are corrected and resubmitted in a subsequent billing cycle. Given that billing submissions and cycles are monthly in most provinces, including Manitoba, a delay of several months between original claim submission and final approval is not uncommon and may explain the improved sensitivity of the case definitions when we extended the time periods. Similarly, errors in data entry of personal health identifiers may also occur in the registry database and may not be corrected until routine audits are performed, thereby causing a delay in the accurate registration of a dialysis patient in the ESRD registry. The combination of these events can result in the frequent mismatch of incident treatment dates, which can likely be overcome only by extending the window of claims or registry entry beyond a calendar year.
There are several implications of our findings. First, our results show that administrative case definitions developed in one province or jurisdiction can be reliably reproduced in another province and achieve a similar degree of accuracy. Provincial and national public health organizations can now use these case definitions for surveillance of ESRD rates across the country. Comparisons across provinces, however, may be limited by differences in coding practices and dataentry standards. Second, we also found that the accuracy of the case definitions was substantially improved by extending the time interval for dialysis claims, and entry into the registry. These findings are likely generalizable to other jurisdictions and may improve the accuracy of case definitions for other chronic diseases. Finally, the high accuracy of the case definitions suggests that they can be used to establish an incident ESRD cohort, which could be linked with other administrative databases (e.g., prescription drug databases), thereby

Table 2: Performance of candidate case definitions of end-stage renal disease (ESRD)* using administrative data over 1 year (2010), with data from the Manitoba Renal Program (MRP) registry database as the reference standard

\begin{tabular}{|c|c|c|c|c|c|}
\hline \multirow[b]{2}{*}{ Case definition } & \multicolumn{2}{|c|}{ Source of data } & \multirow[b]{2}{*}{ No. (\%) of patients } & \multirow[b]{2}{*}{ Measure† } & \multirow[b]{2}{*}{ Value $(95 \% \mathrm{Cl})$} \\
\hline & $\begin{array}{c}\text { Administrative } \\
\text { data }\end{array}$ & $\begin{array}{l}\text { MRP } \\
\text { data }\end{array}$ & & & \\
\hline \multirow{6}{*}{$\begin{array}{l}\text { Any } 1 \text { claim for outpatient } \\
\text { dialysis }\end{array}$} & No & No & $2774(64.1)$ & Sensitivity & $77.0(74.7-79.2)$ \\
\hline & No & Yes & $315 \quad(7.4)$ & Specificity & 93.8 (92.9-94.7) \\
\hline & Yes & No & $183(4.2)$ & PPV & $85.2(83.2-87.2)$ \\
\hline & Yes & Yes & $1053(24.4)$ & NPV & $89.8(88.7-90.9)$ \\
\hline & & & & Accuracy & $88.5(87.4-89.6)$ \\
\hline & & & & $\kappa$ value & $0.73(0.70-0.75)$ \\
\hline \multirow{6}{*}{$\begin{array}{l}\text { Any } 2 \text { claims for outpatient } \\
\text { dialysis }\end{array}$} & No & No & $2791(64.5)$ & Sensitivity & $74.6(72.3-76.9)$ \\
\hline & No & Yes & $347 \quad(8.0)$ & Specificity & $94.4(93.6-95.2)$ \\
\hline & Yes & No & 166 (3.8) & PPV & $86.0(84.0-88.0)$ \\
\hline & Yes & Yes & $1021(23.6)$ & NPV & $88.9(87.8-90.0)$ \\
\hline & & & & Accuracy & $88.1(87.0-89.3)$ \\
\hline & & & & $\kappa$ value & $0.72(0.69-0.74)$ \\
\hline \multirow{6}{*}{$\begin{array}{l}\text { Any } 2 \text { claims for outpatient } \\
\text { dialysis at least } 90 \mathrm{~d} \text { apart }\end{array}$} & No & No & $2872(66.4)$ & Sensitivity & $64.8(62.2-67.3)$ \\
\hline & No & Yes & $482(11.1)$ & Specificity & $97.1(96.5-97.7)$ \\
\hline & Yes & No & 85 (2.0) & PPV & $91.2(89.5-93.0)$ \\
\hline & Yes & Yes & $886(20.5)$ & NPV & $85.6(84.4-86.8)$ \\
\hline & & & & Accuracy & $86.9(85.8-88.0)$ \\
\hline & & & & $\kappa$ value & $0.67(0.65-0.70)$ \\
\hline \multirow{6}{*}{$\begin{array}{l}\text { Any } 2 \text { claims for outpatient } \\
\text { dialysis at least } 90 \text { d apart, } \\
\text { with no gap greater than } \\
21 \text { d }\end{array}$} & No & No & $2883(66.7)$ & Sensitivity & $52.7(50.1-55.4)$ \\
\hline & No & Yes & $647(15.0)$ & Specificity & $97.5(96.9-98.1)$ \\
\hline & Yes & No & $74 \quad(1.7)$ & PPV & $90.7(88.7-92.7)$ \\
\hline & Yes & Yes & $721(16.7)$ & NPV & $81.7(80.4-83.0)$ \\
\hline & & & & Accuracy & $83.3(82.1-84.6)$ \\
\hline & & & & $\kappa$ value & $0.57(0.54-0.59)$ \\
\hline
\end{tabular}




\section{OPEN}

Research

enabling larger studies to examine the effectiveness and safety of medical treatments in this population. This is especially important because randomized controlled trials of drug therapy are uncommon in patients with ESRD, and evidence is urgently needed to inform best medical practice. ${ }^{21,22}$

\section{Strengths and limitations}

Strengths of our study include an independent validation of case definitions for defining ESRD requiring chronic dialysis that were developed in another Canadian province. Another strength was the demonstration of improvements in accuracy with the extension of the time horizon for registry entry and dialysis claims. In addition, Manitoba has a single dialysis provider (the Manitoba Renal Program), and therefore it is an ideal province for the development and validation of case definitions that need to be verified against program-level data.

Like other studies that have explored these case definitions, our study has limitations. A case definition that requires 1 claim for dialysis will overestimate the incidence of chronic dialysis, because it captures patients who require only a single dialysis treatment and then recover kidney function. Conversely, case definitions that require patients to have claims separated by at least 90 days will introduce a survivor bias, because many patients receiving chronic dialysis may die within the first 3 months from other comorbidities. Although patients often may miss or skip dialysis treatments, we chose the 21-day gap to avoid capturing patients with recurrent acute kidney injury who received sporadic dialysis treatments but who should not be characterized as requiring life-sustaining chronic dialysis.

Our study cohort included patients from the regions of northwestern Ontario and rural Saskatchewan, who receive care in Manitoba but for whom dialysis claims are likely submitted and reimbursed in their home provinces. The inclusion of these patients limits the sensitivity of the administra-

Table 3: Performance of candidate case definitions of end-stage renal disease (ESRD)* using administrative data over 5 years (2004-2008), with data from the Manitoba Renal Program (MRP) registry database as the reference standard

\begin{tabular}{|c|c|c|c|c|c|}
\hline \multirow[b]{2}{*}{ Case definition } & \multicolumn{2}{|c|}{ Source of data } & \multirow[b]{2}{*}{ No. (\%) of patients } & \multirow[b]{2}{*}{ Measure $†$} & \multirow[b]{2}{*}{ Value $(95 \% \mathrm{Cl})$} \\
\hline & $\begin{array}{l}\text { Administrative } \\
\text { data }\end{array}$ & $\begin{array}{l}\text { MRP } \\
\text { data }\end{array}$ & & & \\
\hline \multirow{6}{*}{$\begin{array}{l}\text { Any } 1 \text { claim for outpatient } \\
\text { dialysis }\end{array}$} & No & No & $7786(70.9)$ & Sensitivity & $87.6(86.3-89.0)$ \\
\hline & No & Yes & $303(2.8)$ & Specificity & $91.3(90.7-91.9)$ \\
\hline & Yes & No & 739 (6.7) & PPV & $74.4(72.8-76.0)$ \\
\hline & Yes & Yes & $2149(19.6)$ & NPV & $96.2(95.8-96.7)$ \\
\hline & & & & Accuracy & $90.5(89.9-91.2)$ \\
\hline & & & & $\kappa$ value & $0.74(0.73-0.76)$ \\
\hline \multirow{6}{*}{$\begin{array}{l}\text { Any } 2 \text { claims for outpatient } \\
\text { dialysis }\end{array}$} & No & No & $7961(72.52)$ & Sensitivity & $86.0(84.7-87.4)$ \\
\hline & No & Yes & $342(3.12)$ & Specificity & 93.4 (92.9-93.9) \\
\hline & Yes & No & $564(5.14)$ & PPV & $78.9(77.4-80.4)$ \\
\hline & Yes & Yes & $2110(19.22)$ & NPV & 95.9 (95.4-96.3) \\
\hline & & & & Accuracy & $91.8(91.2-92.3)$ \\
\hline & & & & $\kappa$ value & $0.77(0.76-0.78)$ \\
\hline \multirow{6}{*}{$\begin{array}{l}\text { Any } 2 \text { claims for outpatient } \\
\text { dialysis at least } 90 \mathrm{~d} \text { apart }\end{array}$} & No & No & 8495 (77.39) & Sensitivity & $72.0(70.2-73.8)$ \\
\hline & No & Yes & $686(6.25)$ & Specificity & $99.6(99.5-99.8)$ \\
\hline & Yes & No & $30(0.27)$ & PPV & $98.3(97.7-98.9)$ \\
\hline & Yes & Yes & $1766(16.09)$ & NPV & $92.5(92.0-93.1)$ \\
\hline & & & & Accuracy & $93.5(93.0-94.0)$ \\
\hline & & & & $\kappa$ value & $0.79(0.78-0.81)$ \\
\hline \multirow{6}{*}{$\begin{array}{l}\text { Any } 2 \text { claims for outpatient } \\
\text { dialysis at least } 90 \mathrm{~d} \text { apart, } \\
\text { with no gap greater than } \\
21 \mathrm{~d}\end{array}$} & No & No & 8505 (77.48) & Sensitivity & $47.6(45.6-49.6)$ \\
\hline & No & Yes & $1285(11.71)$ & Specificity & 99.8 (99.7-99.9) \\
\hline & Yes & No & $20(0.18)$ & PPV & $98.3(97.6-99.0)$ \\
\hline & Yes & Yes & $1167(10.63)$ & NPV & $86.9(86.2-87.5)$ \\
\hline & & & & Accuracy & $88.1(87.5-88.8)$ \\
\hline & & & & $\kappa$ value & $0.58(0.56-0.60)$ \\
\hline
\end{tabular}


tive case definitions but should not affect specificity. Another limitation was that the administrative case definitions rely on physicians or their practices to code and claim fees for dialysis services appropriately; as such, human errors and oversights in medical billing and coding may have occurred. Nonetheless, we suspect that these errors were limited, because dialysis treatment occurs thrice weekly for most patients, and dialysis fees represent a substantial portion of physician earnings for patients with ESRD. Finally, the case definitions are reliable only for the diagnosis of ESRD, not for non-dialysis chronic kidney disease. Previous studies aimed at developing a case definition for non-dialysis chronic kidney disease have shown poor sensitivity $(<30 \%)$, thereby limiting application. ${ }^{4}$

\section{Conclusion}

Our study showed that accurate case definitions derived from administrative claims data can be developed and validated to identify patients with ESRD receiving chronic dialysis. The optimal case definition of any 2 claims for outpatient dialysis over a 5 -year period achieved greater than $90 \%$ accuracy and could be used to examine long-term trends in disease prevalence. Longer intervals for entry into disease registries and collection of claims data may improve the accuracy of case definitions derived from administrative claims data to identify patients with other chronic disease states.

\section{References}

1. Fetter RB, Shin Y, Freeman JL, et al. Case mix definition by diagnosis-related groups. Med Care 1980;18(Suppl):1-53.

2. Quan H, Khan N, Hemmelgarn BR, et al. Validation of a case definition to define hypertension using administrative data. Hypertension 2009;54:1423-8.

3. Clement FM, James MT, Chin R, et al. Validation of a case definition to define chronic dialysis using outpatient administrative data. BMC Med Res Methodol 2011; $11: 25$

4. Ronksley PE, Tonelli M, Quan H, et al. Validating a case definition for chronic kidney disease using administrative data. Nephrol Dial Transplant 2012; 27:1826-31.

5. James RC, Blanchard JF, Campbell D, et al. A model for non-communicable disease surveillance in Canada: the prairie pilot diabetes surveillance system. Chronic Dis Can 2004;25:7-12.

6. Marrie RA, Yu BN, Leung S, et al. Rising prevalence of vascular comorbidities in multiple sclerosis: validation of administrative definitions for diabetes, hypertension, and hyperlipidemia. Mult Scler 2012;18:1310-9.

7. Yoshino M, Kuhlmann MK, Kotanko P, et al. International differences in dialysis mortality reflect background general population atherosclerotic cardiovascular mortality. 7 Am Soc Nephrol 2006;17:3510-9.
8. Zoccali C, Kramer A, Jager K. The databases: renal replacement therapy since 1989-the European Renal Association and European Dialysis and Transplant Association (ERA-EDTA). Clin 7 Am Soc Nephrol 2009;4(Suppl 1):S18-22.

9. van de Luijtgaarden MW, Jager KJ, Stel VS, et al. Global differences in dialysis modality mix: the role of patient characteristics, macroeconomics and renal service indicators. Nephrol Dial Transplant 2013;28:1264-75.

10. Noordzij M, Jager KJ. Increased mortality early after dialysis initiation: a universal phenomenon. Kidney Int 2014;85:12-4.

11. Manitoba Health and Healthy Living Report, Fune 1, 2008. Winnipeg: Health Information Management Branch; 2008.

12. Glouberman S, Millar J. Evolution of the determinants of health, health policy, and health information systems in Canada. Am 7 Public Health 2003;93:388-92.

13. Strijack B, Mojica J, Sood M, et al. Outcomes of chronic dialysis patients admitted to the intensive care unit. 7 Am Soc Nephrol 2009;20:2441-7.

14. Sood MM, Komenda P, Sood AR, et al. Adverse outcomes among Aboriginal patients receiving peritoneal dialysis. CMAf 2010;182:1433-39.

15. Khan A, Rigatto C, Verrelli M, et al. High rates of mortality and technique failure in peritoneal dialysis patients after critical illness. Perit Dial Int 2012;32:29-36.

16. Lok CE, Oliver MJ, Rothwell DM, et al. The growing volume of diabetes-related dialysis: a population based study. Nephrol Dial Transplant 2004;19:3098-103.

17. Komenda P, Yu N, Leung S, et al. Secular trends in end-stage renal disease requiring dialysis in Manitoba, Canada: a population-based study. CMAf Open 2014. 3:E8-E14.

18. Blanchard JF, Ludwig S, Wajda A, et al. Incidence and prevalence of diabetes in Manitoba, 1986-1991. Diabetes Care 1996;19:807-11.

19. Winkelmayer WC, Schneeweiss S, Mogun H, et al. Identification of individuals with CKD from Medicare claims data: a validation study. Am 7 Kidney Dis 2005;46:225-32.

20. Quinn RR, Laupacis A, Austin PC, et al. Using administrative datasets to study outcomes in dialysis patients: a validation study. Med Care 2010;48:745-50.

21. Strippoli GF, Craig JC, Schena FP. The number, quality, and coverage of randomized controlled trials in nephrology. 7 Am Soc Nephrol 2004;15:411-9.

22. Boulware LE, Tangri N, Ephraim PL, et al. Comparative effectiveness studies to improve clinical outcomes in end stage renal disease: the DEcIDE patient outcomes in end stage renal disease study. BMC Nephrol 2012;13:167.

Affiliations: Section of Nephrology, Department of Medicine (Komenda, Bernstein, Sood, Rigatto, Tangri), University of Manitoba, Winnipeg, Man.; Centre for Global Public Health (Leung), Department of Community Health Sciences, University of Manitoba; Seven Oaks General Hospital (Komenda, Blanchard, Rigatto, Tangri); Department of Community Health Sciences (Yu, Tangri), University of Manitoba; Health Sciences Centre (Bernstein), Winnipeg, Man.; Ottawa Hospital Research Institute (Sood), University of Ottawa, Ottawa, Ont.

Contributors: Paul Komenda, Nancy Yu, Keevin Bernstein, James Blanchard, Manish Sood, Claudio Rigatto and Navdeep Tangri conceived the idea for the study. Nancy Yu and Stella Leung performed the statistical analysis. Paul Komenda, Nancy Yu and Navdeep Tangri drafted the manuscript. All of the authors contributed to the interpretation of results and the revising of the manuscript, approved the final version of the manuscript to be published and agreed to act as guarantors of the work.

Supplemental information: For reviewer comments and the original submission of this manuscript, please see www.cmajopen.ca/content/3/3/ E264/suppl/DC1 